\title{
Congenital patent ductus arteriosus aneurysm
}

INSERM

\section{Source}

INSERM. (1999). Orphanet: an online rare disease and orphan drug data base. Congenital patent ductus arteriosus aneurysm. ORPHA:99072

Congenital patent ductus arteriosus aneurysm is a rare, congenital, arterial duct anomaly characterized by a saccular dilatation of the ductus arteriosus. It is often asymptomatic or presents shortly after birth with respiratory distress, stridor, cyanosis and/or weak cry. Complications, such as rupture, thromboembolism, infection, airway erosion and/or compression of the adjacent thoracic structures, can develop. Spontaneous resolution has been reported. 